\title{
Ethnographic Research on Buying Habits and Consumer Behaviors of Different Genders in Supermarkets
}

\author{
Tianqin Kuang $^{1 *}$, Juanjie Zhang ${ }^{1}$, Pengzhuhui Xiong ${ }^{2}$, Qiuyi Wang ${ }^{2}$
}

\author{
${ }^{1}$ Houde Academy, Shenzhen, Guangdong 518109, China, ${ }^{*}$ Corresponding author. \\ ${ }^{1}$ Shanghai World Foreign Language Academy, Shanghai 200233, China \\ 2'Shanghai Pinghe School, Shanghai 201206, China \\ ${ }^{2}$ Shanghai Shixi High School, Shanghai 200040, China \\ *Email:2320264060@qq.com
}

\begin{abstract}
This paper mainly focuses on the differences in consumption behaviors between men and women, and the method of ethnography will be used to conduct field notes in the work. After the experimental steps of observation and interview, the differences are mainly reflected in the individual's original thinking mode and the impact of the environment at that time. At the same time, when these factors that determine the difference between men and women are found in this work, they can be used as a reference for the improvement of marketing, advertising and promotion to a large extent. As society changes, consumption habits and behaviors will also change accordingly, and the use of ethnography is also a way to keep pace with the understanding of human psychology.
\end{abstract}

Keywords: Ethnographic Research, Buying Habits, Consumer Behaviors, male, female

\section{INTRODUCTION}

A month ago, my friend and I were shopping in a supermarket called "Fresh Hema" in Shanghai. As regular customers of this store, in the work Fresh Hema groceries usually was eaten, usually snacks and drinks. In the supermarket, different customers buy different products. About one or two hundred people in fresh HEMA were seen in this work. Most customers are the elderly - it seems that the elderly have more free time in their daily life, the rest belong to the middle-aged group, and a few are teenagers and children. Among them, several elderly consumers went to the semi-finished product area to buy New Year cakes, roast duck and roast turkey. Middle aged consumers push shopping carts back and forth in the supermarket. They can get what they need in every area by their fast-walking way - it can be seen from their walking frequency that they seem to be in a hurry. Most of those children stay in snack areas and leisure areas children like fun and delicious things. The time in the store is between 5 p.m. and 6 p.m., which is just the time for dinner. A bakery was seen and immediately decided to buy it in the bakery of the supermarket. In the front glass cabinet stood an attractive red velvet cake. The red velvet gave the feeling of the deep red of sponge cake, which was enough to make its delicacy imagined. The red velvet cake was picked up from the glass cabinet in this work. As the counter was approached, there was a conversation which didn't expect in this work. A lady stood behind me, waiting to pay for all the goods she bought. Then about the food bought in the supermarket was talked for a while in this work. However, when the red velvet cake was mentioned, her eyes opened wide. Through the work chat with the lady, she had never seen a man buy red velvet cake and eat it. In this way, they were silent in the work. It was not only silence and confusion, but also shock. How did she come to the conclusion that men don't eat red velvet? Is her behavior reflected in her gender stereotypes? With these questions, my friends and I discussed and thought about all the details. With the work discussion, new problems were raised. In today's society, do men who rarely eat red velvet really exist? However, do men and women actually have different purchase preferences? After considering these problems, the work began to think and study further. 


\section{DEFINE THE QUESTION}

In the process of the work data inquiry, after comparing various data and the information in this work have from field trips, there are huge differences in the consumption behaviors of people of different genders. According to [A survey report on the psychological and behavioral differences between male and female consumers], the researcher indicated that: "The survey found that half of the male respondents do not often go out to shop, the reason they come out to shop is generally the lack of this part of the goods in the home. "[1] Women are very different from men in that they shop a lot, some for more than three hours, and they compare the prices of the same products with those of other places." These data have helped to inform how gender differences in consumer behavior have been study. Therefore, the research question was eventually settled on "How do buying habits and consumption behaviors differ from gender in supermarkets?"

\section{CONCLUDE THE MAIN POINT ABOUT THIS TOPIC}

By summarizing articles and surveys that conducted by different institutions in the supermarkets and shopping malls all over the world in the past decade, a few differences and similarities between two sexes were found in the work:

\subsection{Shopping preferences}

In a supermarket, female consumers pay more attention to the fashion trends and choose more clothes and makeup products while shopping, while male consumers choose electrical appliances, electronic products accounted for a higher proportion.

\subsection{Independence}

Female consumers are more willing to be with their family and friends during shopping, and take suggestions from their peers. Supermarkets then act as a platform to connect kinships and friendships, and become a communication space for women to exchange feelings and transmit information. ${ }^{[2]}$ It is a way for female consumers to express themselves and gain a sense of identity. Although male consumers also enjoy shopping as they gain positive reinforcement from the family's appreciation for their involvement in grocery shopping, their shopping goals are more directional, and they prefer to buy things alone, which improves shopping efficiency.

\subsection{Ambiguity of buying goals}

As female consumers are more likely to plan and write a shopping list before going shopping, they would also buy discounted products back even if they didn't write those items on their lists in advance. ${ }^{[3]}$ On the other hand, their counterparts don't really do that. This conclusion matches the work previous observation where a man only buys the shower gel when he is almost running out of it, while the woman buys it though she still has one left at home.

\subsection{Mindset of buying}

Although both genders pay attention to price during shopping, female consumers tend to be more price sensitive while shopping (37.25\% for males and $62.75 \%$ for females). ${ }^{[4]}$ Also, female consumers appear more focused on the price and discounts of the products and they always compare the same item in different stores to choose the best one to pay for. However, male consumers do not care about prices so much. The most important thing for them is convenience and efficiency to buy the product. This may explain why female consumers tend to buy the discount goods they don't need for future use.

\subsection{Length of time}

As male consumers do the grocery shopping more frequently, the time female consumers spend shopping in the supermarket seems a little longer than males on average every time. ${ }^{[5]}$ The percentage of male consumers who chose to finish shopping in an hour is way more than that of female consumers, and the percentage of female consumers who chose to do the shopping for half of a day is greater. Most male consumers took less time to complete shopping tasks. 


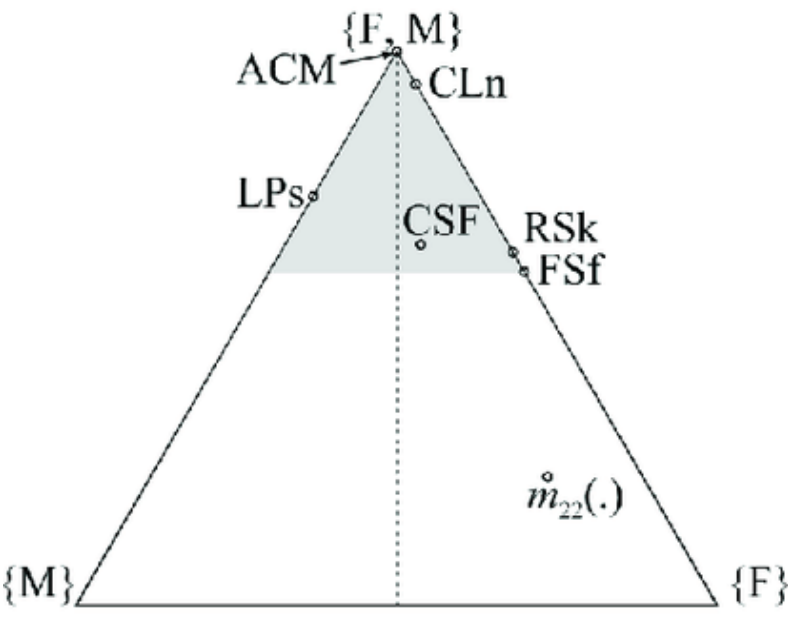

(a) $s_{22}$

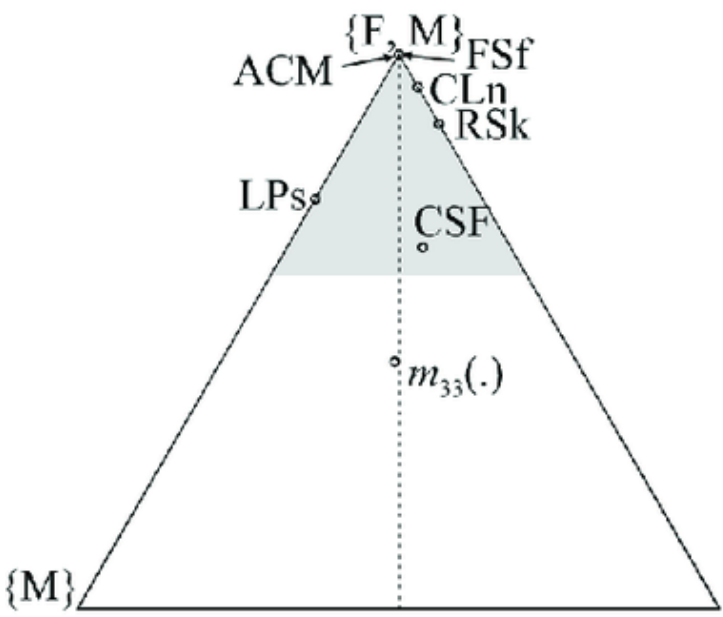

(c) $S_{33}$

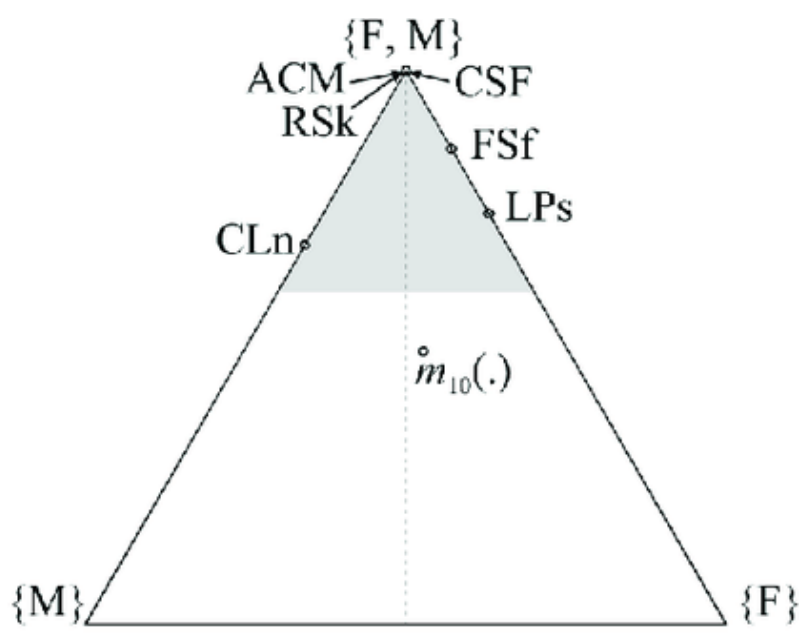

(b) $s_{10}$

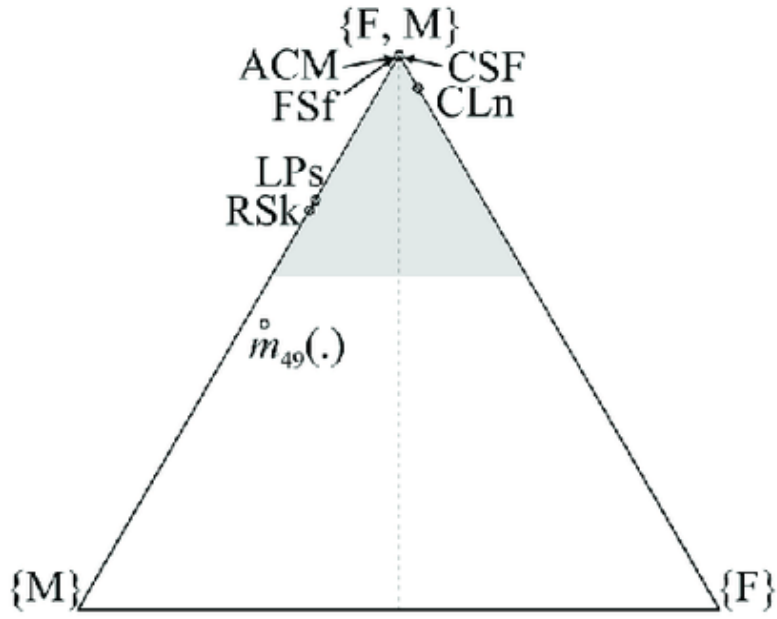

(d) $s_{10}$

Figure 1 Simplex plots of the female and male of the consumers 22 seconds, 10 seconds, 33 seconds and 49 seconds

\section{SOME RESEARCH METHODS ABOUT THE TOPIC HAVE FOUND}

\subsection{Observation}

To continue the study in the research questions, A plan was organized for methods used for future data collection and analysis based on theories from the background information and previous experiences. Both observe and interview was decided during the investigation. To achieve the goal, the work group will be divided into two parts. One will take charge in observation and the other will be doing the interviews. In order to facilitate observation, a Fresh Hema supermarket in Shanghai will be choose as the site, where all problems and research will be carried out. Since customers are most likely to come to the store to buy products at lunchtime on weekends, the observation will be chosen between 11:00 and 12:00 every Saturday. Spending an hour in the supermarket once a week also gives us the opportunity to experience the identity as consumers. This provides us with opportunities and possibilities for further thinking, because the position of this work as observers and target audiences. During the observation, the products purchased by consumers of different genders will be focused on in the supermarket and their motivations for purchasing such products. Meanwhile, purchase activities as consumers will also be conducted in the work. The work will think as a participant in the process of observation, not as an outsider. As well as evaluate and comment on the goods the customers buy and use the data as one of the resources to discover and summarize the pattern behind the consumer behavior in different genders.

Fieldnotes are essential throughout the whole process, of which this work can jot the observations and look closely to different customers in Fresh Hema at the same time. Different products can be written down in this work 
that each consumer buys in the supermarket, and record the findings to better solve the research question.

We will record the respondent's feedback using audio recordings during the observation, and then conduct a group discussion after the interview to review the results of the observation. Therefore, further exploration of the research question will be hold in this work. Due with this question, the fieldnotes will be made in order to figure out the fact of the research question.

\subsection{Interview}

In order to gain more useful information, the interviews at Fresh Hema will also be conducted to different groups of people in the work.

First, people who are shopping at Fresh Hema will be interviewed. They will be divided into three big groups in general: the elder, the middle-aged, and teenagers. Then, each of the three groups will be divided by their gender. Therefore, the interviewees will be differentiated by six groups. The interview questions for consumers are as shown in Table 1.

Table 1 The set of questions for the consumers at Fresh Hema

\begin{tabular}{|c|l|}
\hline 1 & $\begin{array}{l}\text { Are you a returned customer or coming for the } \\
\text { first time? What do you think of Fresh Hema? }\end{array}$ \\
\hline 2 & $\begin{array}{l}\text { Why do you choose to come shopping at Fresh } \\
\text { Hema? How did you get here? }\end{array}$ \\
\hline 3 & $\begin{array}{l}\text { What's your family structure? Who is responsible } \\
\text { for shopping in your family? Do you have any } \\
\text { kids? }\end{array}$ \\
\hline 4 & $\begin{array}{l}\text { Are you used to shopping alone or shopping } \\
\text { with your friends or family? Why? }\end{array}$ \\
\hline 5 & $\begin{array}{l}\text { How often do you go shopping and how long } \\
\text { do you spend on shopping every time? }\end{array}$ \\
\hline 6 & $\begin{array}{l}\text { What's your shopping method? Do you prepare } \\
\text { a shopping list before coming to the } \\
\text { supermarket? }\end{array}$ \\
\hline 7 & $\begin{array}{l}\text { Do you have a specific budget before coming? } \\
\text { Do special offers and promotions affect your } \\
\text { decisions? Will you buy things you don't need } \\
\text { for now? Why? }\end{array}$ \\
\hline 8 & $\begin{array}{l}\text { How do you like shopping? (Is it entertaining or } \\
\text { tiring?) }\end{array}$ \\
\hline
\end{tabular}

Next, the clerks who offer help to the consumers at every different section in Fresh Hema will be interviewed. The interview questions for clerks are as shown in Table 2.
Table 2 The set of questions for the clerks at Fresh Hema

\begin{tabular}{|l|l|}
\hline 1 & $\begin{array}{l}\text { Are there many consumers coming to your } \\
\text { section every day compared to other sections? }\end{array}$ \\
\hline 2 & $\begin{array}{l}\text { What are the characteristics of the consumers } \\
\text { coming to your section? }\end{array}$ \\
\hline 3 & $\begin{array}{l}\text { Among the consumers you offered help, are } \\
\text { most of them male customers or female } \\
\text { customers? What kinds of questions do you get } \\
\text { more often? }\end{array}$ \\
\hline 4 & $\begin{array}{l}\text { Are there often sales promotions in your area? } \\
\text { What is the consumers' reaction toward these } \\
\text { activities? Are people who choose to buy the } \\
\text { products increasing? }\end{array}$ \\
\hline
\end{tabular}

According to the work experiences living in Shanghai, most customers at Fresh Hema in Shanghai use the self-service machine to checkout by scanning WeChat code or Alipay code on their phones. As the customers just need to scan the pricing codes behind the products and that's quite easy, the consumers will be talked during this process.

Meanwhile, the interview between us and the clerks will take place at different sections in the market. Since clerks are usually really busy during lunchtime, especially the ones who work in the seafood and semifinished meal sections in Hema (this section also acts as a mini restaurant), they will be interviewed as quickly as possible. It will be more efficient if they answer in short sentences or just a few words. Customers are the main respondents so we're not going to focus very much on clerks.

Although people may feel nervous and give fake answers while strangers are interviewing them, they will be told that this is an anonymous survey, and it will not offend their privacy (no personal questions designed like where do you live or what's your phone number). We'll ask the interviewees' permission to record the dialogue. It was an awkward experience to have a one-question-oneanswer conversation without any ups and downs in the previous interviews, so we're trying to conduct it in a natural way by using a gentle and mild tone.

After collecting all the data, this work need, will be reviewed every single part of the observation and interviews by going through the fieldnotes and listening to the recordings.

\section{CONCLUSION}

When this work first came into contact with this research topic, curious and a little nervous was full of the work. Before this month, many opportunities didn't 
appear to take field trips. At the same time, this course was a new experience for us, having the opportunity to work with people from all over the world with different experiences. In the first few weeks of the course, a problem has been developed with Ethnography. So, the readings and sites that hoped to find was located in the work. When the park was found for the field trip, the work officially conducted. The walk used to happen in the park a lot, so the environment is familied. In the process of the daily observation, the data that collected in the work would be referred to conduct interviews. This method can be used to make the Field Note more real and more referenceable.

To my surprise, many details was found that had not found before during the field investigation, such as the appearance of the trees in front of the park changed, and the number of new people in the park with people coming and going every day. These are small things that I wouldn't have paid attention to before. But after I came into contact with Ethnographic Methods, the work seemed to have a sense of attention to such details in my daily life. The things were started to be notice that might not have noticed before and wonder if IT's something this work can write down for its future self. Learning Ethnography would pay more attention to the details, and this was realized when this work went to the park for a field trip. When the work looks at people or objects, it goes from the superficial to the detailed. When making field notes, it is also necessary to fill in the details -because the observers, should record things without cutting them down.

Certainly, the experience of making a proposal in group activities was also unforgettable. In this past two weeks, the work team felt nervous and didn't know what to do and how to do when making the proposal at first, but eventually the work overcame the difficulties and came to present a complete presentation of a proposal that was not perfect but they all worked hard to make.

\section{REFERENCES}

[1] DinK. (2014) Gender Differences in consumer behavior in shopping malls http://www.199it.com/archives/251924.html.

[2] Kara A. Arnold, Constanza Bianchi. (2001) Relationship Marketing, Gender, and Culture: Implications for Consumer Behavior. Advances in Consumer Research, 28: 100-105.

[3] Katherine Schaeffer. (2019) Among U.S. couples, women do more cooking and grocery shopping than men https://www.pewresearch.org/facttank/2019/09/24/among-u-s-couples-women-domore-cooking-and-grocery-shopping-than-men/

[4] Ting Wang, Yimei Zheng, Yi Fang. (2014)An investigation report on the psychological and behavioral differences of male and female consumers in shopping. http://www.haoword.com/gongzuozongjie/diaocha/ 57988.html

[5] Beynon, Malcolm J., et al. (2010) Gender Differences in Supermarket Choice. European Journal of Marketing, 44: 267-290. 